\title{
Effect of Sufentanil Preemptive Analgesia on Anesthesia Recovery Period of Patients undergoing Thoracoscopic Surgery and Nursing Observation
}

\author{
KEMEI REN REN AND RONG NING ${ }^{1}$ AND TING RAN*
}

Department of Anesthesiology, 'Department of Thoracic and Cardiovascular Surgery, Fuling Central Hospital of Chongqing City, Chongqing 408000, China

Ren et al.: Effect of Sufentanil on Patients undergoing Thoracoscopic Surgery

\begin{abstract}
We aim to investigate the effectiveness of intravenous injection of sufentanil before the induction of general anesthesia in patients undergoing thoracoscopic surgery to control pain in the postoperative recovery period and analyze its impact on the qualified rate of nursing and the occurrence of nursing adverse events. Selected 146 patients who underwent thoracoscopic surgery in our department from February 2018 to May 2020.73 patients with intraoperative intravenous injection of sufentanil were selected as the experimental group and 73 patients with intraoperative intravenous injection of normal saline were selected as the control group. Compared both groups with visual analogue scales scores and Bruggrmann comfort scale scores at 30 min, $1 \mathrm{~h}, 2 \mathrm{~h}$ and $3 \mathrm{~h}$ after operation. At the same time, compared both groups with heart rate, blood oxygen saturation, mean arterial pressure and bispectral index values during the anesthesia recovery period and extubation and after extubation and qualified rate of nursing and its nursing adverse events. The heart rate, mean arterial pressure and bispectral index values of the two groups of patients at the time of extubation and 5 min after extubation were significantly different $(\mathbf{p}<\mathbf{0 . 0 5})$. Visual analogue scale scores and Bruggrmann comfort scale scores of both groups at $30 \mathrm{~min}, 1 \mathrm{~h}, 2 \mathrm{~h}$ and $3 \mathrm{~h}$ after surgery had significant differences $(\mathrm{p}<0.05)$. It had significant differences of both groups in the qualified rate of nursing and its adverse events $(p<0.05)$, which were statistically significant. For patients undergoing thoracoscopic surgery, intravenous injection of sufentanil before general anesthesia can promote better postoperative pain. Sufentanil is considered as a potential auxiliary drug for preemptive analgesia, which is used to manage postoperative pain in short-term surgery and is worthy of clinical promotion.
\end{abstract}

Key words: Sufentanil, preemptive analgesia, thoracoscopy, hypertension

At present, thoracoscopic surgery is developing rapidly in thoracic surgery. It is a convenient, less traumatic and quick recovery operation method. It is a minimally invasive operation method and the discharge time of patients after surgery is significantly shortened ${ }^{[1,2]}$. Sufentanil and Remifentanil are opioid receptor agonists. They have significant analgesic effects during surgery. They are widely used in thoracic surgery. They have a short onset time and quick recovery time. Cough is considered to be the most common adverse reaction of sufentanil ${ }^{[3,4]}$. The postoperative anesthesia recovery period is often accompanied by wound pain, which can cause stress response and hemodynamic changes. Therefore, it is very important to control the patient's pain during the recovery period and can reduce postoperative complications, such as hypertension, wound infection, painful shock, etc., ${ }^{[5]}$. Often, postoperative pain during anesthesia recovery period will affect the quality of the patient's recovery; the recovery period pain will reduce patient compliance and lead to mental depression, etc. The pharmacological properties of fentanyl have prompted the production of many new fentanyl analogues, including sufentanil, alfentanil, remifentanil, lofentanil, etc., which can interact with the central specificity receptors to reduce the pain of patients during surgery ${ }^{[6]}$. However, the use of high-dose of sufentanil during surgery may cause postoperative cough, aspiration and even respiratory depression. Most scholars believe that preemptive analgesia can reduce pain and stress response, maintain

*Address for correspondence

E-mail: gfrkm@126.com 
hemodynamic stability, reduce intraoperative bleeding and the incidence of cardiovascular and cerebrovascular events. The application of preemptive analgesia of sufentanil can not only improve the qualified rate of nursing in the anesthesia recovery period of thoracic surgery patients, but also reduce the occurrence of nursing adverse events ${ }^{[7]}$. In this study, we observed the analgesic effect of sufentanil preemptive analgesia on patients undergoing thoracoscopic surgery in our hospital from February 2018 to May 2020 during the anesthesia recovery period and analyzed its impact on nursing quality. Selected 146 patients who underwent thoracoscopic surgery from February 2018 to May 2020. 73 patients who received intraoperative intravenous injection of sufentanil as the experimental group and 73 patients who received intraoperative intravenous injection of normal saline as the control group. 42 males and 31 females included in experimental group, aged from $18 \mathrm{y}$ to $67 \mathrm{y}$ old, the average age is about $(40.39 \pm 10.64)$ y old; in the control group, 39 males and 34 females included in control group, aged from $19 \mathrm{y}$ to $68 \mathrm{y}$ old, the average age is about (39.75 \pm 11.91$)$ y old. Both groups had no significant difference in age and gender $(\mathrm{p}>0.05)$ and they were comparable. Inclusion criteria includes patients with neurological diseases such as unconscious disorders, mental abnormalities and cognitive impairment and good cardiopulmonary function; all included patients are adults, all over $18 \mathrm{y}$ old; the preoperative anesthesia classification of the patient was graded from I to II according to the American Association of Anesthesiologists (ASA); the patient and family members understand the situation, agree and sign the informed consent; approved by the hospital's ethics committee. Exclusion criteria includes patients suffers from severe cardiopulmonary dysfunction and other diseases; the patient has a mental illness and cannot cooperate with the doctor; the patient has a history of allergies to fentanyl drugs. After the patient enters the operating room from the ward, he is given an infusion and monitored the changes of the patient's Heart Rate (HR), Systolic Blood Pressure (SBP), Bispectral Index (BIS), Oxygen Saturation $\left(\mathrm{SpO}_{2}\right)$, etc. Patients in the experimental group were given an intravenous injection of $100 \mu \mathrm{g}$ of sufentanil $30 \mathrm{~min}$ before the operation ends and control group was also given an intravenous injection of $2 \mathrm{ml}$ of $0.9 \%$ sodium chloride solution 30 min before the end of the operation. The wound comfort of both groups was evaluated at various time periods after surgery; the Bruggrmann Comfort Scale (BCS) was used to evaluate the score. The higher the score, the higher the wound comfort and vice versa. The Visual Analogue Scale (VAS) of the patient was evaluated at various time points after the operation. The lower the VAS score, the lower the pain, conversely the higher the score, the higher the pain. The $\mathrm{SpO}_{2}, \mathrm{HR}$, Mean Arterial Pressure (MAP) and other conditions of both groups were recorded during awakening, extubation, 5 min and 15 min after extubation and BIS was monitored. Recorded the nursing quality standard rate and nursing adverse events of both groups. We adopt Statistical Package for the Social Sciences (SPSS) 20.0 to analyze the data. Use mean \pm standard deviation $(\overline{\mathrm{x}} \pm \mathrm{s})$ to indicate quantitative data. Compare both groups by independent sample $\mathrm{t}$ test, analyze the enumeration data by $\chi^{2}$ test, $\mathrm{p}<0.05$ proves that the divergence possesses statistical significance. The results showed that the $\mathrm{HR}, \mathrm{SpO}_{2}$ and MAP of both groups at different time points did not change much, both groups were almost the same, so it had no statistical significance $(p>0.05)$. Compared with experimental group, HR and MAP values of patients in control group at the time of extubation and 5 min after extubation were significantly different. The control group had higher scores, so it had statistical significance $(p<0.05)$. The BIS value of extubation and 5 min after extubation of control group was higher than experimental group, with significant difference and it was of statistical significance $(\mathrm{p}<0.05)$ (Table 1$)$. Result analysis showed that the VAS scores of both groups increased after operation, but all decreased after $3 \mathrm{~h}$. Control group had significantly higher VAS scores than experimental group at $30 \mathrm{~min}, 1 \mathrm{~h}, 2 \mathrm{~h}$ and $3 \mathrm{~h}$ after operation and the divergence possessed statistical significance $(p<0.05)$. Both groups had significant differences in VAS scores of $30 \mathrm{~min}, 1 \mathrm{~h}, 2 \mathrm{~h}$ and $3 \mathrm{~h}$ after the operation, which possessed statistical significance $(\mathrm{p}<0.05)$ (Table 2$)$. Result analysis showed that BCS scores of both groups increased after operation, but all decreased after $3 \mathrm{~h}$. VAS scores of control group were remarkably lower than experimental group at 30 min, $1 \mathrm{~h}, 2 \mathrm{~h}$ and $3 \mathrm{~h}$ after operation and the divergence had statistical significance $(\mathrm{p}<0.05)$, both groups VAS scores of $30 \mathrm{~min}, 1 \mathrm{~h}, 2 \mathrm{~h}$ and $3 \mathrm{~h}$ after operation were significantly different, which had statistical significance $(\mathrm{p}<0.05)$ (Table 3). The qualified rate of nursing in experimental group was $98.6 \%$ while in control group it was $76.7 \%$. Both groups had a significant difference, so it possessed statistical significance $(p<0.05)$. The adverse events rate in experimental group was $1.37 \%$ while in control group it was $23.28 \%$. The divergence 
had statistical significance $(\mathrm{p}<0.05)$ (Table 4). Many scholars have researched and put forward the concept of Enhanced Recovery After Surgery (ERAS) to improve care quality in perioperative period. The purpose is to reduce the damage of organ function and accelerate the process of restoring its function. In this concept, great attention has been paid to postoperative pain management. The acute pain after thoracoscopic surgery occurs in the early time of surgery ends and is not often taken seriously in clinical practice ${ }^{[8]}$. Poor management of postoperative pain might cause complications and prolonged recovery time, which concerns chronic pain development and the quality of life reduction ${ }^{[9]}$. At present, opioids such as morphine have been widely used for postoperative analgesia. However, their side effects, such as addicts, constipation, nausea, cough and itching, etc. ${ }^{[10]}$, prompt us to seek new drugs or combine existing drugs to reduce the consumption of opioids against these adverse reactions and provide ideas for ideal postoperative analgesia. Fentanyl anesthetics are highly fat-soluble and can quickly cross the blood-brain barrier, it works quickly and takes a short time ${ }^{[3,11]}$. It is generally used as an analgesic supplement and regional anesthesia, as well as severe chronic pain and postoperative pain management ${ }^{[12]}$. The forms of fentanyl anesthetics include sublingual tablets, nasal sprays, transdermal patches and injection preparations. Normally we use fentanyl transdermal patches to treat chronic pain patients who require continuous opioid analgesia. The generally recommended blood concentration is $12 \mathrm{ng} /$ $\mathrm{ml}$ while easing pain and $10-20 \mathrm{ng} / \mathrm{ml}$ while anesthesia ${ }^{[13]}$. Besides analgesic effects, fentanyl and its analogs will inhibit the respiratory system, shrink pupils and produce drowsiness and euphoria. The most common side effects include nausea, dizziness, vomiting, fatigue, headache and constipation. Repeated use of fentanyl causes a higher tolerance and dependence. High doses may cause respiratory arrest and pulmonary edema and death ${ }^{[14-16]}$. Here, we found that sufentanil can effectively prevent postoperative pain and significantly reduce the occurrence of nursing adverse events for patients undergoing thoracoscopic surgery. In addition, the use of sufentanil before surgery increases the rate of satisfaction of care and makes patients more satisfy. Initially, sufentanil was considered to have an analgesic effect similar to morphine and the combination of sufentanil and morphine have great effect on easing pain, which proves that sufentanil may have other analgesic mechanism ${ }^{[17]}$. However, recent studies have shown that sufentanil can also inhibit the reuptake of norepinephrine in serum in vitro. In addition, sufentanil plays an immune role in affecting lymphocyte activity during tissue injury by regulating Interleukin (IL)-12 and IL-10 secretion, which may also help to ease pain ${ }^{[18-20]}$. The results of this study proved that the nursing qualified rate of experimental group was $98.6 \%$ while in control group it was $76.7 \%$. Both groups had a significant difference, which possessed statistical significance $(p<0.05)$. The adverse events rate in experimental group was $1.37 \%$ while in control group it was $23.28 \%$, the divergences had statistical significance $(\mathrm{p}<0.05)$. Compared with experimental group, HR and MAP values in control group at the time of extubation and 5 min after extubation were significantly different. Control group was higher than the other. BIS value in control group at the time of extubation and 5 min after extubation was higher than experimental group, with significant differences and statistical significance $(p<0.05)$ and the VAS and BCS scores of the two groups increased after surgery, but decreased at $3 \mathrm{~h}$ after operation. The VAS and BCS scores of the control group at $30 \mathrm{~min}, 1 \mathrm{~h}, 2 \mathrm{~h}$ and $3 \mathrm{~h}$ after surgery were significantly different from those of the experimental group. There were significant differences in the VAS and BCS scores at $30 \mathrm{~min}, 1 \mathrm{~h}, 2$ $\mathrm{h}, 3 \mathrm{~h}$ after the operation within the group and both had statistical significance $(\mathrm{p}<0.05)$. VAS is two commonly used scales for evaluating postoperative pain ${ }^{[21]}$. In this study, we use VAS assessment. But this study also has limitations. First of all, we have not studied the best dose of sufentanil in clinic for postoperative hyperalgesia. In the future, we will study whether lowdose sufentanil has the same effect without side effects. Secondly, our research mainly discusses the short-term effects of sufentanil on postoperative pain management and care. It is necessary to conduct a long-term study on pain threshold changes after a few weeks. In summary, our research proves that for patients who accept thoracoscopic surgery, intravenous injection of sufentanil before general anesthesia can promote better postoperative pain control with fewer side effects. Therefore, sufentanil is considered as a potential preemptive analgesic adjuvant drug to manage postoperative pain in short-term surgery. 


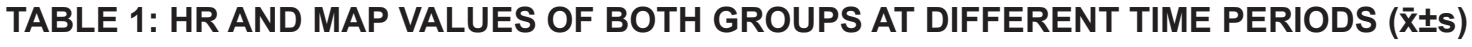

\begin{tabular}{lccccc}
\hline Group & Item & Awake & Extubation & $\begin{array}{c}5 \text { min after } \\
\text { extubation }\end{array}$ & $\begin{array}{c}15 \text { min after } \\
\text { extubation }\end{array}$ \\
\hline Experimental group & $\mathrm{HR}$ (beats/min) & $75.53 \pm 7.67$ & $73.69 \pm 7.05$ & $76.03 \pm 8.03$ & $74.85 \pm 7.32$ \\
& $\mathrm{MAP}(\mathrm{mm} \mathrm{Hg})$ & $93.55 \pm 7.03$ & $91.05 \pm 6.96$ & $92.75 \pm 7.35$ & $93.89 \pm 7.26$ \\
& $\mathrm{SpO}_{2}(\%)$ & $97.04 \pm 2.23$ & $95.94 \pm 2.05$ & $96.84 \pm 2.32$ & $95.93 \pm 2.41$ \\
& $\mathrm{BIS}$ & $76.46 \pm 7.94$ & $85.03 \pm 8.04$ & $88.04 \pm 4.03$ & $94.96 \pm 3.15$ \\
Control group & $\mathrm{HR}(\mathrm{beats} / \mathrm{min})$ & $74.95 \pm 7.68$ & $76.68 \pm 7.13$ & $79.64 \pm 8.76$ & $76.95 \pm 7.74$ \\
& $\mathrm{MAP}(\mathrm{mm} \mathrm{Hg})$ & $94.54 \pm 7.34$ & $95.33 \pm 7.85$ & $95.57 \pm 7.03$ & $93.51 \pm 7.36$ \\
& $\mathrm{SpO}_{2}(\%)$ & $96.45 \pm 2.43$ & $94.32 \pm 2.52$ & $95.83 \pm 2.55$ & $94.04 \pm 3.05$ \\
& $\mathrm{BIS}$ & $75.94 \pm 6.99$ & $90.34 \pm 6.03$ & $92.94 \pm 4.35$ & $94.46 \pm 3.63$ \\
\hline
\end{tabular}

TABLE 2: COMPARISON OF VAS SCORES OF BOTH GROUPS IN DIFFERENT TIME PERIODS AFTER SURGERY $(\overline{\mathbf{x}} \pm \mathbf{s})$

\begin{tabular}{lcccc}
\hline & 30 min after operation & $1 \mathrm{~h}$ after operation & $2 \mathrm{~h}$ after operation & $3 \mathrm{~h}$ after operation \\
\hline Experimental group & $1.56 \pm 0.37$ & $2.74 \pm 0.50$ & $4.26 \pm 0.51$ & $2.32 \pm 0.46$ \\
Control group & $2.04 \pm 0.46$ & $3.53 \pm 0.62$ & $5.63 \pm 0.64$ & $2.89 \pm 0.42$ \\
\hline
\end{tabular}

TABLE 3: COMPARISON OF BCS SCORES OF BOTH GROUPS IN DIFFERENT TIME PERIODS AFTER SURGERY ( $\overline{\mathbf{x}} \pm \mathbf{s})$

\begin{tabular}{lcccc}
\hline & 30 min after operation & $1 \mathrm{~h}$ after operation & $2 \mathrm{~h}$ after operation & $3 \mathrm{~h}$ after operation \\
\hline Experimental group & $2.53 \pm 0.41$ & $3.76 \pm 0.53$ & $3.84 \pm 0.56$ & $1.87 \pm 0.43$ \\
Control group & $1.73 \pm 0.38$ & $2.64 \pm 0.48$ & $2.99 \pm 0.54$ & $1.02 \pm 0.32$ \\
\hline
\end{tabular}

\section{TABLE 4: COMPARISON OF THE QUALIFIED RATE OF NURSING AND NURSING ADVERSE EVENTS BETWEEN BOTH GROUPS}

\begin{tabular}{|c|c|c|c|c|c|c|c|c|c|}
\hline \multirow{2}{*}{ Group } & \multirow{2}{*}{ Cases } & \multicolumn{2}{|c|}{ Excellent } & \multicolumn{2}{|c|}{ Good } & \multicolumn{2}{|c|}{ Adverse events } & \multicolumn{2}{|c|}{$\begin{array}{l}\text { Quality of care up to } \\
\text { standard }\end{array}$} \\
\hline & & Cases & $\%$ & Cases & $\%$ & Cases & $\%$ & Cases & $\%$ \\
\hline Control group & 73 & 24 & 32.88 & 32 & 43.84 & 17 & 23.28 & 56 & 76.7 \\
\hline $\begin{array}{l}\text { Experimental } \\
\text { group }\end{array}$ & 73 & 39 & 53.42 & 33 & 45.21 & 1 & 1.37 & 72 & 98.6 \\
\hline$\chi^{2}$ & & 10.843 & & 7.341 & & 8.183 & & 11.563 & \\
\hline $\mathrm{p}$ & & 0.001 & & 0.015 & & 0.009 & & 0.001 & \\
\hline
\end{tabular}

\section{Conflict of interests:}

The authors declared no conflict of interest.

\section{REFERENCES}

1. Oizumi H. Thoracoscopic Surgery. Kyobu geka 2018;71(10):838-42.

2. Heller JA, Bhora FY, Heller BJ, Cohen E. Roboticassisted thoracoscopic lung surgery: Anesthetic impact and perioperative experience. Minerva Anestesiol 2017;84(1):10814.

3. Scholz J, Steinfath M, Schulz M. Clinical pharmacokinetics of alfentanil, fentanyl and sufentanil. Clin Pharmacokinet 1996;31(4):275-92.
4. Van de Donk $\mathrm{T}$, Ward $\mathrm{S}$, Langford $\mathrm{R}$, Dahan $\mathrm{A}$. Pharmacokinetics and pharmacodynamics of sublingual sufentanil for postoperative pain management. Anaesthesia 2018;73(2):231-7.

5. Zielinski J, Morawska-Kochman M, Zatonski T. Pain assessment and management in children in the postoperative period: A review of the most commonly used postoperative pain assessment tools, new diagnostic methods and the latest guidelines for postoperative pain therapy in children. Adv Clin Exp Med 2020;29(3):365-74.

6. Porela-Tiihonen S, Kokki H, Kokki M. An up-to-date overview of sublingual sufentanil for the treatment of moderate to severe pain. Expert Opin Pharmacother 2020;21(12):1407-18.

7. Zhao Z, Lv B, Zhao X, Zhang Y. Effects of OPRM1 and $\mathrm{ABCB} 1$ gene polymorphisms on the analgesic effect and dose of sufentanil after thoracoscopic-assisted radical resection of lung cancer. Biosci Rep 2019;39(1):BSR20181211. 
8. Li Q, Yao H, Xu M, Wu J. Dexmedetomidine combined with sufentanil and dezocine-based patient-controlled intravenous analgesia increases female patients' global satisfaction degree after thoracoscopic surgery. J Cardiothorac Surg 2021;16(1):17.

9. Yang J, Hao Z, Li W, Duan C, Fan X, Xin J, et al. The efficacy and safety of paravertebral block combined with parecoxib during video-assisted thoracic surgery: A randomized controlled trial. J Pain Res 2020;13:355.

10. Wen QP, Miao Z, Wu P, Wang J, Zhou FC, Lin Y, et al. Whole-course application of dexmedetomidine combined with ketorolac in nonnarcotic postoperative analgesia for patients with lung cancer undergoing thoracoscopic surgery: A randomized control trial. Pain Physician 2020;23(2):E185-93.

11. Väänänen A, Kuukasjärvi M, Tekay A, Ahonen J. Spinal and epidural sufentanil and fentanyl in early labour. Acta Anaesthesiol Scand 2019;63(10):1413-8.

12. Lee W, Gao X, Tang J, Li A, Zhu Y, Ling X, et al. Postoperative sufentanil intravenous patient-controlled analgesia within the first $24 \mathrm{~h}$ : A retrospective study. Ann Palliat Med 2020;9(6):3932-7.

13. Vergari A, Cortegiani A, Rispoli M, Coluzzi F, Deni F, Leykin Y, et al. Sufentanil Sublingual Tablet System: From rationale of use to clinical practice. Eur Rev Med Pharmacol Sci 2020;24(22):11891-9.

14. Warner L, Branstad A, Guevara LH, Bitterman LM, Pingree M, Nicholson W, et al. Malfunctioning sufentanil intrathecal pain pump: A case report. J Med Case Rep 2020;14(1):1-4.

15. Yang Y, Wu J, Li H, Ye S, Xu X, Cheng L, et al. Prospective investigation of intravenous patient-controlled analgesia with hydromorphone or sufentanil: Impact on mood, opioid adverse effects and recovery. BMC Anesthesiol 2018;18(1):1-37.
16. Zhi M, Diao Y, Liu S, Huang Z, Su X, Geng S, et al. Sufentanil versus fentanyl for pain relief in labor involving combined spinal-epidural analgesia: A systematic review and metaanalysis of randomized controlled trials. Eur J Clin Pharmacol 2020;76(4):501-6.

17. Loflin R, Koyfman A. When used for sedation, does ketamine increase intracranial pressure more than fentanyl or sufentanil? Ann Emerg Med 2014;65(1):55-6.

18. Minkowitz HS, Candiotti K. The role of sublingual sufentanil nanotabs for pain relief. Expert Opin Drug Deliv 2015;12(5):845-51.

19. Yang Y, Teng X, Zhu J. Sufentanil blunts the myocardial stress induced by tracheal intubation in older adult patients with coronary heart disease better than equipotent fentanyl. Ann Palliat Med 2020;9(6):3909-14.

20. Pokorná P, Š́ma M, Vobruba V, Bašková M, Posch L, Slanař O. Sufentanil pharmacokinetics in a full-term neonate treated with extracorporeal membrane oxygenation: A case report. Perfusion 2019;34(5):433-6.

21. Sung YT, Wu JS. The visual analogue scale for rating, ranking and paired-comparison (VAS-RRP): A new technique for psychological measurement. Behav Res Methods 2018;50(4):1694-715.

This is an open access article distributed under the terms of the Creative Commons Attribution-NonCommercial-ShareAlike 3.0 License, which allows others to remix, tweak, and build upon the work non-commercially, as long as the author is credited and the new creations are licensed under the identical terms

This article was originally published in a special issue, "Novel Therapeutic Approaches in Biomedicine and Pharmaceutical Sciences" Indian J Pharm Sci 2021:83(6) Spl Issue “226-230" 